\title{
TRANSLATIONAL NOTES
}

SciBX

Science-Business eXchange

\section{Biogen interacts with target discovery}

\section{By Tim Fulmer, Senior Writer}

Biogen Idec Inc. is taking advantage of advances in the study of protein-protein interactions to generate the first comprehensive human interactome. In collaboration with Harvard Medical School researchers, the company will map the interaction network of 10,000-15,000 human proteins over the next 4 years, which could provide Biogen with a wealth of new targets in immunological and neurological diseases.

The move is part of Biogen's decision to reignite its target-discovery efforts. ${ }^{1}$

"We will initially focus on 200 proteins that we believe are important in neurological and immunological diseases, our key focus areas, and will then expand from there," Biogen EVP of R\&D Douglas Williams told SciBX.

The goal is "to make Biogen an innovator in defining new pathways and targets. Whereas before we were learning about new targets by reading papers, we now want to get out ahead and be the ones publishing those papers," he said.

Those new targets will "potentially lead to first-in-class drugs, which strengthen our pipeline and make it more competitive," Williams added.

Although the proteome is defined as the set of all proteins expressed by the genome of an organism, the interactome is the set of all interactions between those proteins. Because protein-protein interactions drive almost all cellular functions, complete knowledge of an organism's interactome could provide drug developers with an exhaustive list of potential therapeutic targets.

Over the last decade many academic labs have mapped out interactomes in a variety of small organisms, including yeast ${ }^{2}$ and Caenorhabditis elegans. ${ }^{3}$ The majority of those studies relied on the yeast two-hybrid approach, which measures interactions between any two prespecified proteins. ${ }^{4}$

More recently, mass spectrometry-based approaches to interactome mapping have gained popularity and been used to map the interactomes of yeast, ${ }^{5}$ Escherichia coli ${ }^{6}$ and Mycoplasma pneumoniae. ${ }^{7}$ However, no one has yet published a comprehensive map of the human interactome using either approach.

To generate such a map, Biogen has set up a collaboration with Steven Gygi and J. Wade Harper at Harvard Medical School, two researchers who have developed a mass spectrometry-based platform to study protein-protein interactions. Gygi is associate professor of cell biology. Harper is professor of cell biology and molecular pathology.

In prior papers published in Cell in 2009 and Nature in 2010, the researchers used their method to map portions of the human interactome, including the ubiquitinating enzyme interaction network and the autophagy interaction network. ${ }^{8,9}$

"We believe the Harvard team's platform is the most accurate out there for identifying protein-protein interactions, and that's why we chose it to generate our human interactome," Biogen CSO Spyros Artavanis-Tsakonas told SciBX.

Artavanis-Tsakonas has firsthand experience with the platform. Prior to joining Biogen in March, Artavanis-Tsakonas collaborated with Gygi to generate a Drosophila interactome. The resulting Drosophila Protein Interaction Map (DPiM), published in Cell in 2011, encompassed 566 protein complexes involved in a variety of cell signaling pathways. ${ }^{10}$

"The clear advantage of the mass spec-based approach over the yeast two-hybrid approach is that the former allows you to measure not only interactions between any two proteins but also simultaneous interactions between multiple proteins that form ensembles and complexes in the cell," said Artavanis-Tsakonas. "That is very important because those complexes play a crucial role in cell signaling pathways and are potential drug targets."

As the first step of the program, the Harvard team will generate baseline maps of the human interactome in a number of healthy cell types, including 3T3 cells, which are a standard fibroblast cell line, as well as CNS and immune cells. Next, Biogen and the Harvard researchers will generate interactome maps of neuronal and immune cell lines that model various disease phenotypes.

Finally, Biogen and the Harvard group will use statistical and data analysis to measure differences between the healthy and disease interactome maps. Such differences could be qualitative, such as the absence or presence of a particular protein-protein interaction or complex, or quantitative, such as decreased or increased levels of a particular interaction or complex.

Generating even a single interactome map of a particular healthy or diseased cell type will be a time-consuming and data-intensive process. Each of the proteins potentially included in the map will have to be expressed in a given cell type, isolated using affinity purification, put through mass spectrometry to identify all of its interaction partners and analyzed using statistical tools to rule out false-positive interactions.

Nonetheless, once the healthy and disease interactome maps are completed, differences between the two maps can be used to quickly identify variations in protein-protein interactions that may signify potential therapeutic targets.

It should then be possible to engineer those variations into animals to characterize them in an in vivo setting. Based on the in vitro and 


\section{ANALYSIS}

\section{TRANSLATIONAL NOTES}

in vivo data, researchers then will be in a position to decide how best to target a particular interaction in a given disease.

Harvard will own any IP resulting from the Interactome Program. Biogen Idec will have the option to negotiate exclusive rights to patentable discoveries. Biogen is providing funding in the single-digit millions.

Fulmer, T. SciBX 5(29); doi:10.1038/scibx.2012.747

Published online July 26, 2012

\section{REFERENCES}

1. Schaeffer, S. BioCentury 20(27), A10-A11; July 2, 2012

2. Ito, T. et al. Proc. Natl. Acad. Sci. USA 98, 4569-4574 (2001)
3. Li, S. et al. Science $303,540-543$ (2004)

4. Brückner, A. et al. Int. J. Mol. Sci. 10, 2763-2788 (2009)

5. Krogan, N.J. et al. Nature 440, 637-643 (2006)

6. Hu, P. et al. PLoS Biol. 7, e96; published online April 28, 2009; doi:10.1371/journal.pbio.1000096

7. Kühner, S. et al. Science 326, 1235-1240 (2009)

8. Sowa, M.E. et al. Cell 138, 389-403 (2009)

9. Behrends, C. et al. Nature 466, 68-76 (2010)

10. Guruharsha, K.G. et al. Cell 147, 690-703 (2011)

COMPANIES AND INSTITUTIONS MENTIONED

Biogen Idec Inc. (NASDAQ:BIIB), Weston, Mass. Harvard Medical School, Boston, Mass. 